\title{
CHARACTERISTICS OF HARDENED CONCRETE INCORPORATING CEMENT KILN DUST (CKD) AND SILICA FUME (SF)
}

\author{
Ahmed Islam M. Abdullah ${ }^{* 1}$, Rafik Khairy Abdelwahab ${ }^{1}$, Arafa Elsayed Elhelloty ${ }^{2}$ \\ and Mohammed Taha Nooman ${ }^{2}$ \\ ${ }^{1}$ Civil Engineering Dept., Al-Azhar University, Osman buildings, Qena , Egypt \\ ${ }^{2}$ Civil Engineering Dept., Faculty of Engineering, Al-Azhar University, Cairo, Egypt \\ *Corresponding Author E-mail: abdullah.a.i@azhar.edu.eg
}

\begin{abstract}
In this research characteristics of hardened concrete containing cement kiln dust and silica fume as a partial replacement of cement were studied. These characteristics inclusion on compressive strength, electrical conductivity, water sorptivity and accelerated corrosion, for each mixture X-ray diffraction were carried out for determined mineralogical analysis of the representative concrete sample. Concrete specimens were prepared with different ratios of CKD and constant ratio $15 \% \mathrm{SF}$ as a partial replacement by weight of cement. The test results had revealed that The use of CKD as partial replacement of cement in combination with SF in concrete were shown best performance than use CKD only. The amount of 20\% CKD in the presence $15 \% \mathrm{SF}$ as a partial replacement by weight of cement were the optimum ratios can be used in concrete mixtures without lower on compressive. At 5\%,10\% and 15\% CKD with constant $15 \% \mathrm{SF}$ at frequencies $0.12,1.0$ and $10 \mathrm{kHz}$, the electrical conductivity were increased with increased CKD amount, whereas beyond 15\% CKD efficiency of electrical conductivity were decreased with increase CKD amount at all frequencies. But at $(10 \%$ to $25 \%$ ) CKD, sorptivity value were increased with increase CKD amount when comparison with control mixture. The replacing of cement with CKD and SF, give - about - the same corrosion rate which clear shown from XRD analysis.
\end{abstract}

KEYWORDS: Partial replacement of cement, Cement kiln dust (CKD), Silica fume (SF),Compressive strength, Electrical connectivity, Water sorptivity, Accelerated corrosion, XRD.

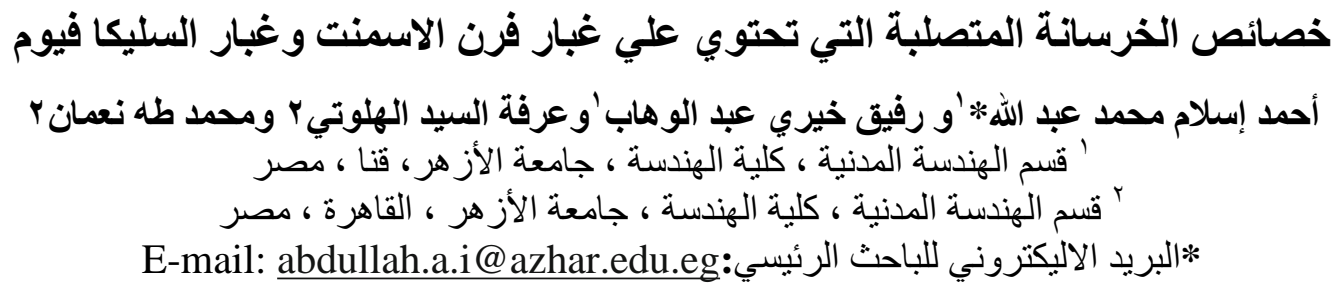

*البريد الاليكتروني للباحث الرئيسي:E-mail: abdullah.a.i@azhar.edu.eg

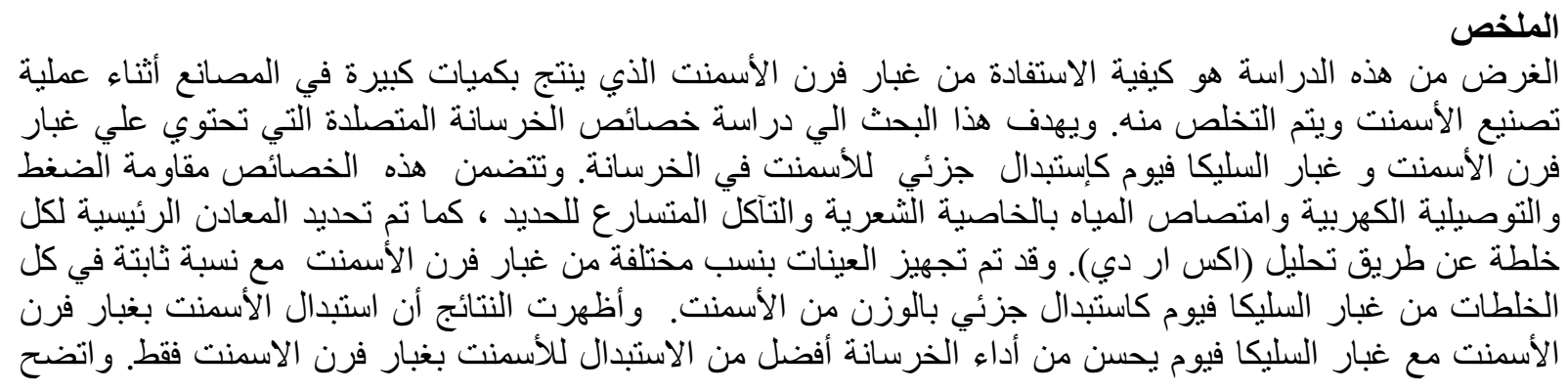




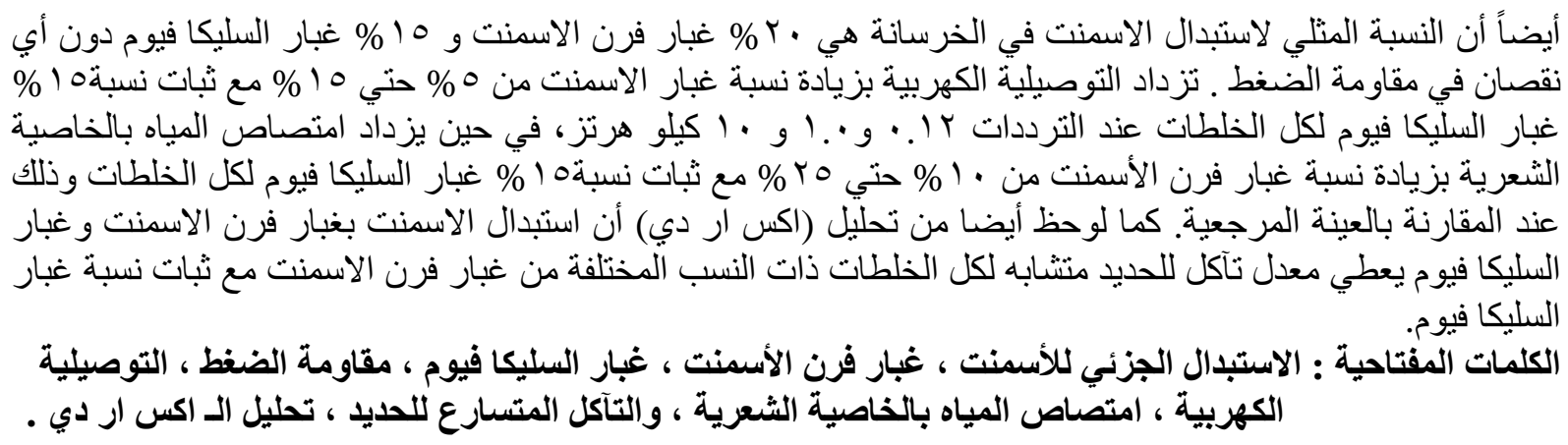

\section{1-INTRODUCTION}

Both of Cement kiln dust (CKD) and silica fume (SF) are a by-product materials during manufacturing. using CKD and SF in concrete production more significant for dispose of them in usefully produce. It was found from the experimental tests and previous research, the use of CKD individually as a partial replacement of cement in concrete lead to decrease in strength. It was observed a progressive decrease in flow ability and mechanical strength properties of concrete with increasing CKD content replacement [1]. XRD analysis of cement kiln dust have revealed that the major component was limestone $\left(\mathrm{CaCO}_{3}\right)$, whereas the minor components were quartz $\left(\mathrm{SiO}_{4}\right)$ together with small quantity of sodium chloride $(\mathrm{NaCl})$, gypsum $\left(\mathrm{CaSO}_{4}\right)$, arcanite $\left(\mathrm{K}_{2} \mathrm{SO}_{4}\right)$, sulfospurite $\left[2\left(\mathrm{C}_{2} \mathrm{~S}\right) \cdot \mathrm{CaSO}_{4}\right]$ and spurite $\left[2\left(\mathrm{C}_{2} \mathrm{~S}\right) \cdot \mathrm{CaCO}_{3}\right]$ [2]. Silica fume is a highly effective pozzolanic material due to its extreme fineness (0.1 microns) and consists primarily of amorphous (non-crystalline) silicon dioxide $\left(\mathrm{SiO}_{2}\right)$. While small particle size of silica fume is beneficial in particle-packing, it also results in increased water demand to achieve workability needed for good compaction[3]. It is possible to use of the CKD as partial replacement of cement, in combination with pozzolanic materials in certain mortar mixed designs without lowering the main characteristics of the product[4]. Pozzolanic materials such as silica fume is used in concrete because of its fine particles, large surface area and high $\mathrm{SiO} 2$ content [5]. Silica fume as a pozzolana when properly used it as certain percent, it can enhance various properties of concrete both in the fresh as well as in hardened states like cohesiveness, strength, permeability and durability [6]. In the general applications, part of cement may be replaced by a much smaller quantity of silica fume. For example, one part of cement can be replaced with 0.25 to 0.33 part of silica fume (mass to mass) without losing in the strength, provided the content of water remains constant[7]. The optimum silica fume replacement percentage varies from $10 \%$ to $15 \%$ replacement level, compressive strength decreases when the cement replacement is above $15 \%$ of silica fume [8].

\section{2- EXPERIMENTAL PROGRAM}

\section{1- Materials used}

According to the Egyptian standard specifications for concrete aggregates [9], sand with fineness modulus equal 2.59 and specific gravity of 2.57 was used, whereas the coarse aggregate used was dolomite maximum normal size $(5-14 \mathrm{~mm})$ and specific gravity of 2.74 . Cement (CEM I-52.5N) used was fresh product from Sina factory and complies to E.S.S 4756/2013[10]. CKD was obtained from the El Nahda cement factory in Qena, Egypt. SF was obtained from Egyptian Company for Ferroalloys (Alferrosilicon), Edfo factory , Aswan , Egypt. SF was confirming to ACI 234R-96 [7]. The chemical composition of Portland cement, CKD and SF were shown in table 1. Potable water free from salts, oils, acids, sugars and other harmful substances was used for mixing and curing of specimens. Sikament-163M was used as super plasticizer, for highly effective water reducing agent, density (at $20^{\circ} \mathrm{C}$ ) $1.200 \pm 0.005 \mathrm{~kg} / \mathrm{liter}$ (ASTM C494), Appearance / Colour is brown liquid and recommended dosage is $0.6-2.5 \%$ by weight of cement, The experimental dosage was $2.0 \%$ by weight of cement.

\section{2- Mixtures Proportions}

In this experimental investigation, control concrete mix to achieve compressive strength of 50 $\mathrm{N} / \mathrm{mm} 2$ at the age of 28 days was done according to ECP 203-2007[11].The use CKD with different percentages $5 \%, 10 \%, 15 \%, 20 \%$ and $25 \%$ and a fixed proportion of silica fume (SF) 
$15 \%$ as partial replacement by weight of (OPC). The mixtures proportions for $1 \mathrm{~m} 3$ in all concrete mixtures were shown in table 2.

Table.1 Chemical composition of Cement, Cement kiln dust and Silica fume

\begin{tabular}{|c|c|c|c|}
\hline \multirow{2}{*}{$\begin{array}{c}\text { Chemical Composition, } \\
\%\end{array}$} & \multicolumn{3}{|c|}{ Sample } \\
\hline & CEM I $(52.5 \mathrm{~N})$ & CKD & $\mathbf{S F}^{*}$ \\
\hline SiO2 & 20.48 & 12.27 & 93.79 \\
\hline $\mathrm{Al2O3}$ & $\begin{array}{c}15.06 \\
5.23\end{array}$ & 2.27 & 0.36 \\
\hline $\mathrm{Fe} 2 \mathrm{O3}$ & $\begin{array}{l}3.96 \\
\mathbf{3 . 4 0}\end{array}$ & 3.70 & 1.48 \\
\hline $\mathrm{CaO}$ & $\begin{array}{c}2.12 \\
62.72\end{array}$ & 45.28 & 0.33 \\
\hline MgO & 1.67 & 1.49 & 0.41 \\
\hline SO3 & 3.20 & 2.59 & 0.19 \\
\hline $\mathrm{Na2O}$ & 0.33 & 0.31 & 0.43 \\
\hline K2O & 0.27 & 5.68 & 0.62 \\
\hline Cl & 0.02 & 8.06 & 0.05 \\
\hline L.O.I & 3.20 & 17.38 & 1.63 \\
\hline
\end{tabular}

*Note: These average values are supplied by the manufacturer.

Table.2 Mix Proportions

\begin{tabular}{|c|c|c|c|c|c|c|c|}
\hline Mix* & $\begin{array}{c}\text { Cement } \\
\left(\mathrm{kg} / \mathrm{m}^{3}\right)\end{array}$ & $\begin{array}{c}\text { water } \\
\left(\mathrm{kg} / \mathrm{m}^{3}\right)\end{array}$ & $\begin{array}{c}\text { crushed } \\
\text { stone } \\
\left(\mathrm{kg} / \mathrm{m}^{3}\right)\end{array}$ & $\begin{array}{c}\text { sand } \\
\left(\mathrm{kg} / \mathrm{m}^{3}\right)\end{array}$ & $\begin{array}{c}\text { CKD } \\
\left(\mathrm{kg} / \mathbf{m}^{3}\right)\end{array}$ & $\begin{array}{c}\text { SF } \\
\left(\mathrm{kg} / \mathrm{m}^{3}\right)\end{array}$ & $\begin{array}{c}\text { SP } \\
\left(\mathrm{kg} / \mathbf{m}^{3}\right)\end{array}$ \\
\hline \multicolumn{7}{|c|}{ Control Mixture } \\
\hline Mix-00-00 & 360 & 144 & 1260 & 630 & $\mathbf{0 . 0}$ & $\mathbf{0 . 0}$ & 7.2 \\
\hline \multicolumn{7}{|c|}{ Cement kiln dust with Silica fume Mixtures } \\
\hline Mix-05-15 & 288 & 144 & 1260 & 630 & 18 & 54 & 7.2 \\
\hline Mix-10-15 & 270 & 144 & 1260 & 630 & 36 & 54 & 7.2 \\
\hline Mix-15-15 & 252 & 144 & 1260 & 630 & 54 & 54 & 7.2 \\
\hline Mix-20-15 & 234 & 144 & 1260 & 630 & 72 & 54 & 7.2 \\
\hline Mix-25-15 & 216 & 144 & 1260 & 630 & 90 & 54 & 7.2 \\
\hline
\end{tabular}

*Mix designation is( Mixture-Cement kiln dust\%-Silica fume\%)

\section{3- ANALYSIS OF TEST RESULTS}

\section{1- Compressive strength}

The cubes specimens $(150 \mathrm{~mm}$ X150mm X150 mm) was tested for compressive strength at the end of 28 days. The specimen was tested after the surface gets dried. The test is conducted in a Compression Testing Machine with a capacity of $2000 \mathrm{kN}$ and loading rate 0.6 $\mathrm{N} / \mathrm{mm} 2 / \mathrm{sec}$, according to Egyptian Code for the design and implementation of concrete structures , tests guide C203[12]. The load applied on the smooth sides without shock and increased continuously till the specimen failed. Fig. 1 shows the variation of compressive strength in mixtures content cement kiln dust and silica fume versus control mixture at 28 days. When comparison with control mixture (0\% Cement kiln dust and $0 \%$ Silica fume), its observed the compressive strength for mixtures; (5\% Cement kiln dust and 15\% Silica fume), (10\% Cement kiln dust and 15\% Silica fume), (15\% Cement kiln dust and 15\% Silica fume) and (20\% Cement kiln dust and 15\% Silica fume) are increased with $18.34 \%, 11.48 \%, 6.17 \%$ and $3.55 \%$ respectively. Whereas at mixture (25\% Cement kiln dust and $15 \%$ Silica fume), 
compressive strength are decreased with $3.69 \%$.

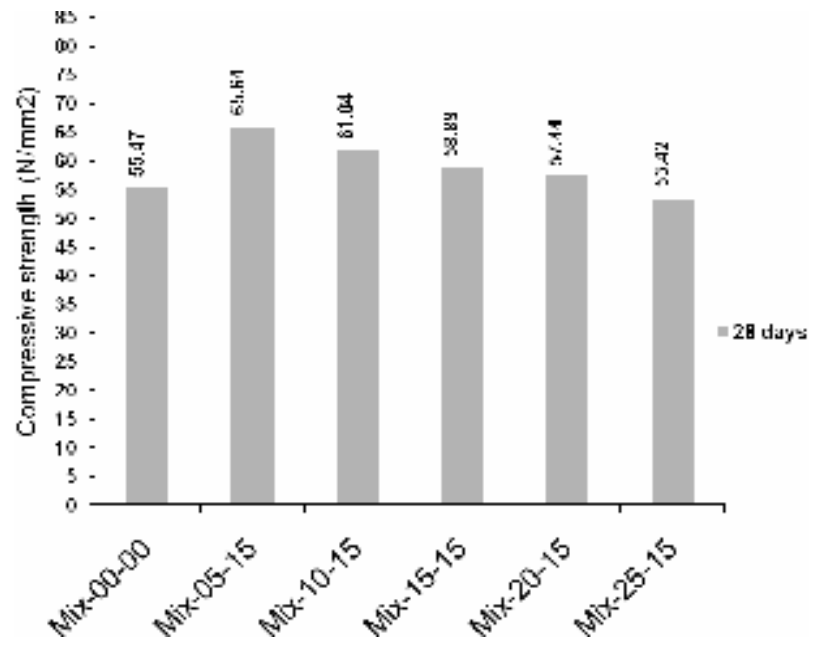

Fig.1 Compressive strength of mixtures content CKD $5 \%, 10 \%, 15 \%, 20 \%$ and $25 \%$ with constant $15 \%$ SF versus control mixture at 28 days

\section{2- Electrical conductivity}

Two electrodes (copper plate with $0.50 \mathrm{~mm}$ thick) were placed and fixed with cement paste over the entire two face of the specimen $(150 \mathrm{~mm} \times 150 \mathrm{mmx} 150 \mathrm{~mm}$ cube). It was applied to maintain a constant and uniform stress distribution. Measurements is performed by using alternating current $(\mathrm{AC})$ at room temperature over frequency range of $(0.12,1.0,10$ and $100 \mathrm{kHz}$ ) using a RCL bridge model [Stanford Res. Model: SR-720] at age of 28 days. The setup of the experiment is shown schematically in Fig.2. Test were conducted on samples of control mixture and mixtures contained of cement kiln dust and silica fume to measurement the electrical conductivity $(\sigma)$ and dielectric constant $(\varepsilon)$ of concrete.
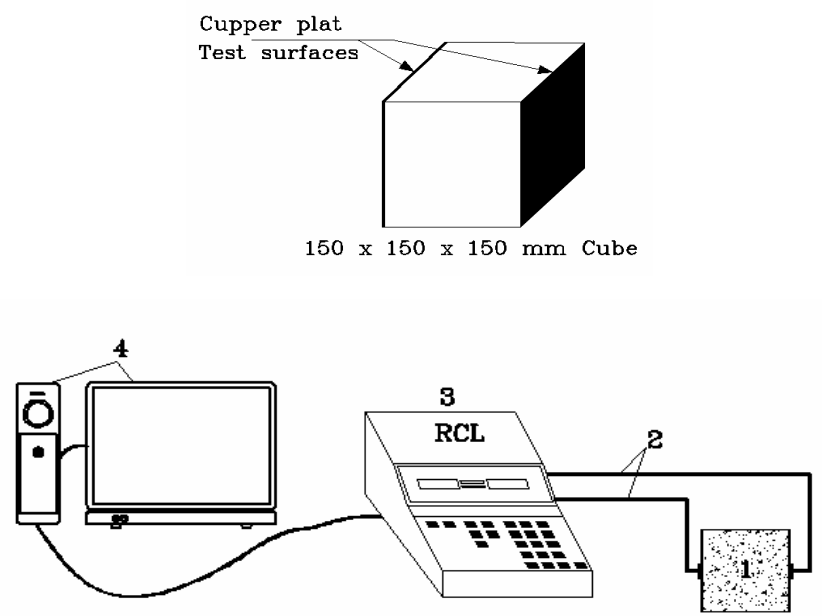

Fig.2 A schematic representation of RCL bridge setup

1-Sample with side copper plates,

2-Well shielded current,

3-RCL bridge,

4-Controlling computer.

Fig.3 show the effect of Cement kiln dust $(5 \%, 10 \%, 15 \%, 20 \%$ and $25 \%)$ with constant ratio $15 \%$ of Silica fume on electrical conductivity $(\sigma)$ at frequencies $0.12,1,10$ and $100 \mathrm{kHz}$ after 28 days. The electrical conductivity $(\sigma)$ increase with increase cement kiln dust up to ratio $15 \%$ at frequencies $0.12,1$ and $10 \mathrm{kHz}$. A slight increase by frequency increasing up to $10 \mathrm{kHz}$ for this three mixtures; (5\% Cement kiln dust and 15\% Silica fume), (10\% Cement kiln dust and $15 \%$ Silica fume) and (15\% Cement kiln dust and 15\% Silica fume). 
The electrical conductivity $(\sigma)$ for mixture (20\% Cement kiln dust and $15 \%$ Silica fume) less than control mixture $(0 \%$ Cement kiln dust and $0 \%$ Silica fume), but its value increase with increase AC frequency. The smallest value for electrical conductivity $(\sigma)$ are observed for mixture (25\% Cement kiln dust and 15\% Silica fume), but this value increase with increase AC frequency. Generally it is observed the value of electrical conductivity $(\sigma)$ directly proportional to the increase of $\mathrm{AC}$ frequency for all mixtures. The presence of CKD affected the location and height of the conductivity peaks. By increasing the CKD from $2.5 \%$ to $7.7 \%$, the conductivity maximum increased. With further addition (10\%), the height of the conductivity maximum decreased [13].

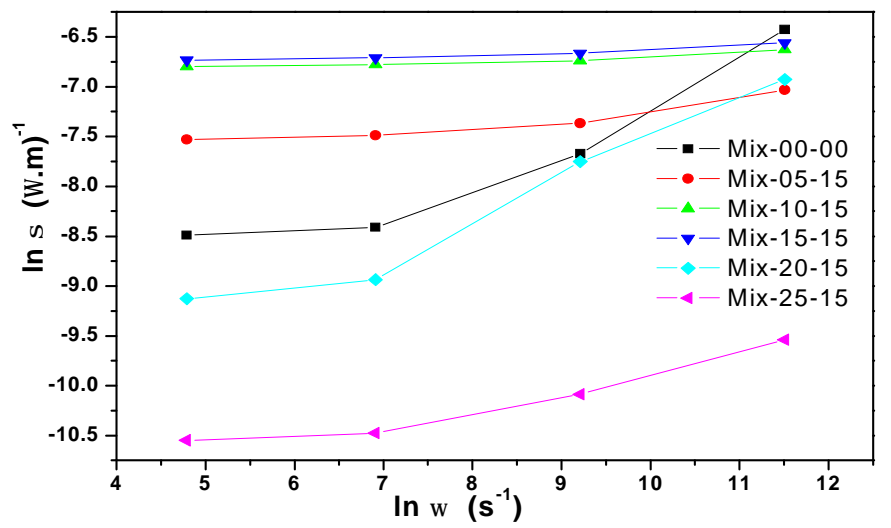

Fig.3 Effect of CKD $(5 \%, 10 \%, 15 \%, 20 \%$ and $25 \%)$ and constant $15 \%$ SF on electrical conductivity $(\sigma)$ at frequencies $0.12,1,10$ and $100 \mathrm{kHz}$ at 28 days.

Fig.4 show the effect of Cement kiln dust $(5 \%, 10 \%, 15 \%, 20 \%$ and $25 \%)$ with constant ratio $15 \%$ of Silica fume on dielectric constant $(\varepsilon)$ at frequencies $0.12,1,10$ and $100 \mathrm{kHz}$ after 28 days. In general for all mixtures contained of cement kiln dust and silica fume, the dielectric constant $(\varepsilon)$ less than control mixture at all frequencies. That's mean by using cement kiln dust and silica fume in concrete mixtures lead to decrease the dielectric constant. For mixture (20\% Cement kiln dust and $15 \%$ Silica fume) at frequency $1.0 \mathrm{kHz}$ the dielectric constant $(\varepsilon)$ increase with $4.22 \%$ when compared with control mixture. Whereas mixture (15\% Cement kiln dust and $15 \%$ Silica fume) at frequency $0.12 \mathrm{kHz}$ the dielectric constant ( $\varepsilon$ ) a slight decrease with $5.01 \%$ when compared with control mixture. For all mixtures, the dielectric constant $(\varepsilon)$ are decrease with increase $\mathrm{AC}$ frequency. It is observed the value of dielectric constant $(\varepsilon)$ inversely proportional to the increase of $\mathrm{AC}$ frequency for all mixtures.

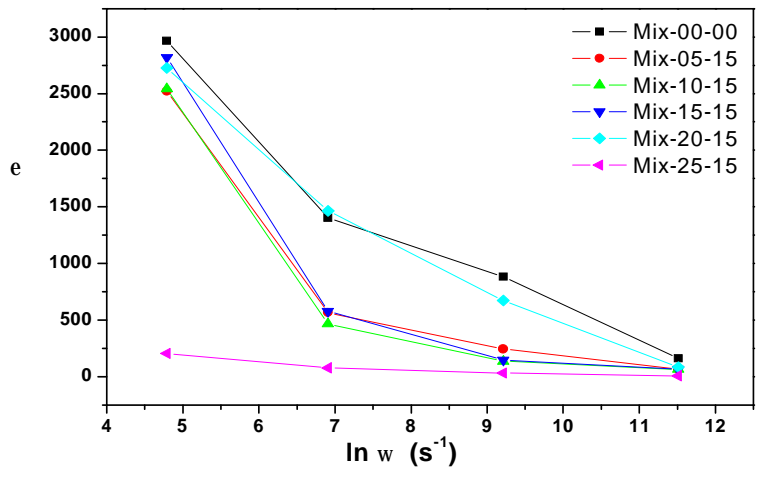

Fig.4 Effect of CKD $(5 \%, 10 \%, 15 \%, 20 \%$ and $25 \%)$ and constant $15 \%$ SF on dielectric constant ( $(\varepsilon)$ at frequencies $0.12,1,10$ and $100 \mathrm{kHz}$ at 28 days. 


\subsection{1- Relationship between electrical conductivity and compressive strength}

The relationship between the electrical conductivity $(\sigma)$ and compressive strength for concrete mixtures containing on different ratios $5 \%, 10 \%, 15 \%, 20 \%$ and $25 \%$ of cement kiln dust and $15 \%$ silica fume after 28 days are showing in Fig.5. At all frequencies $0.12,1,10$ and 100 $\mathrm{kHz}$, it was found the electrical conductivity $(\sigma)$ increase with decrease compressive strength up to $15 \%$ cement kiln dust, whereas observed beyond $15 \%$ cement kiln dust, the electrical conductivity $(\sigma)$ sharp decreases with decrease compressive strength up to $25 \%$ cement kiln dust.
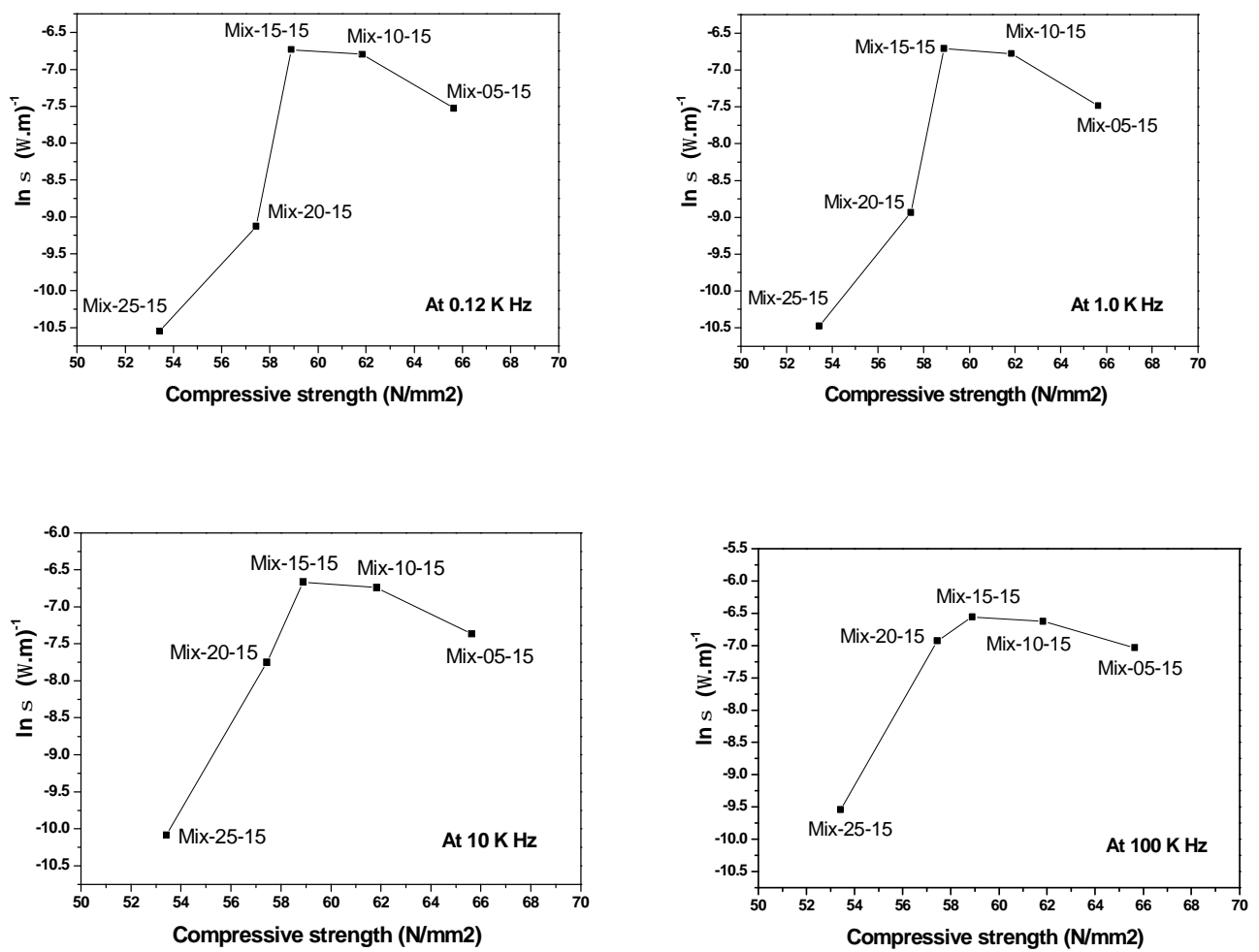

Fig.5 Relationship between electrical conductivity $(\sigma)$ and compressive strength for mixtures content different ratios $5 \%, 10 \%, 15 \%, 20 \%$ and $25 \%$ of $\mathrm{CKD}$ and $15 \% \mathrm{SF}$ at different frequencies $(\mathrm{kHz})$

\section{3- Water sorptivity}

Water sorptivity test is a quick test to determined the rate of water absorption through dry concrete sample by capillary suction. The specimens with dimensions $70 \mathrm{~mm}$ X $70 \mathrm{~mm}$ and 30 $\mathrm{mm}$ height were dried in 70o $\mathrm{C}$ oven for 4 days and then left to cool for the following 24 hours in dry conditions. The sides of the test specimens were coated with water proof epoxy in order to achieve the conditions of unidirectional flow through test specimen. All specimens were dipped in the water in a vertical position with one surface in partially immersed to a depth of $5 \mathrm{~mm}$ and the other open to the atmosphere. Weights of the specimen after epoxy coating were taken as initial weight at time 0 . At fixed intervals time during the test (typically $3,7,9,12,16,20,25,30,60,90,120,150,180,210,240,270$ and 300 minutes) the samples were removed from water then excess water blotted off with cloth and the sample weighed. Fig.6 shows schematic of sorptivity testing. Test were conducted on samples of control mixture and mixtures contained of cement kiln dust and silica fume at 28 days. 

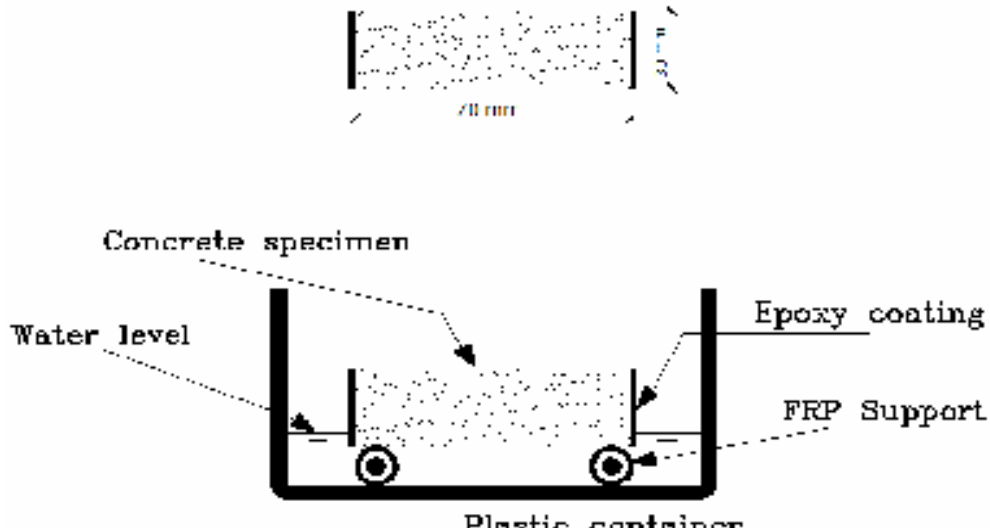

Fig.6 Schematic of Sorptivity Testing

Fig.7 shows the variation of sorptivity values for mixtures with different ratios of Cement kiln dust $5 \%, 10 \%, 15 \%, 20 \%$ and $25 \%$ in the presence $15 \%$ Silica fume versus control mixture at 28 days. it was observed at amount of (5\% Cement kiln dust and $15 \%$ Silica fume) as partial replacement of cement, the sorptivity value was decreased with $18.34 \%$. Whereas the sorptivity value were increased with $35.99 \%, 46.71 \%, 57.79 \%$ and $94.81 \%$ at amount of $10 \%, 15 \%, 20 \%$ and $25 \%$ Cement kiln dust in the presence $15 \%$ Silica fume as partial replacement of cement respectively when compared with control mixture.

When CKD was incorporated in all mixtures while keeping the amount of cement fixed, strength of mortars were higher than the control mix. However, it was found in the cases studied that there is no beneficial increase in strengths beyond 5\% CKD addition. The sorptivity increased with the addition of CKD [14].

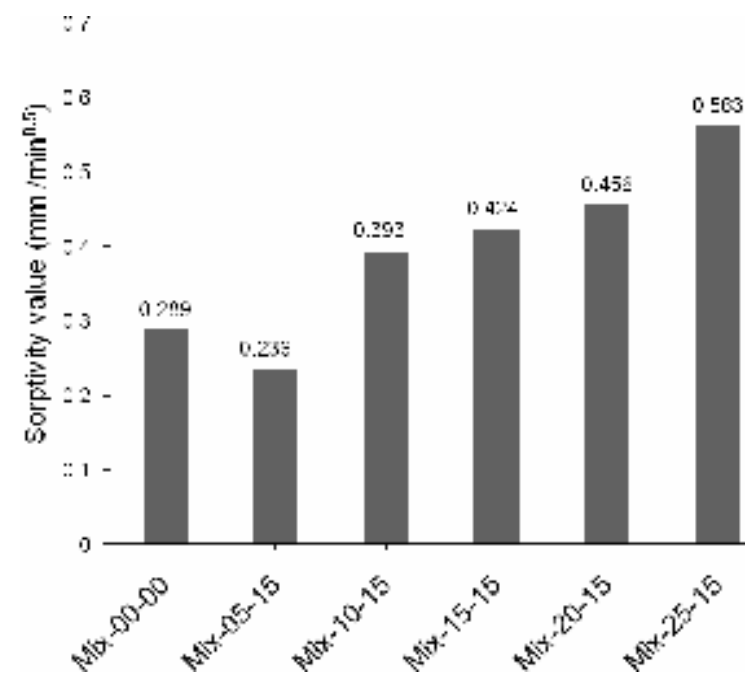

Fig.7 Sorptivity values for mixtures content CKD $(5 \%, 10 \%, 15 \%, 20 \%$ and25\%) and constant $15 \%$ SF versus control mixture at 28 days

\subsection{1- Relationship between sorptivity and compressive strength}

By analysis of the present test results to determined the relationship between the 28-day water sorptivity and compressive strengths of concrete mixtures with different ratios of content cement kiln dust in the presence 15\% silica fume Fig.8, it was observed the water sorptivity increase with decreasing of compressive strength. It was found for mixture content $5 \%$ cement kiln dust and $15 \%$ silica fume which have the highest value of compressive strength are showed the smallest value of water sorptivity when comparing with the other mixtures. 


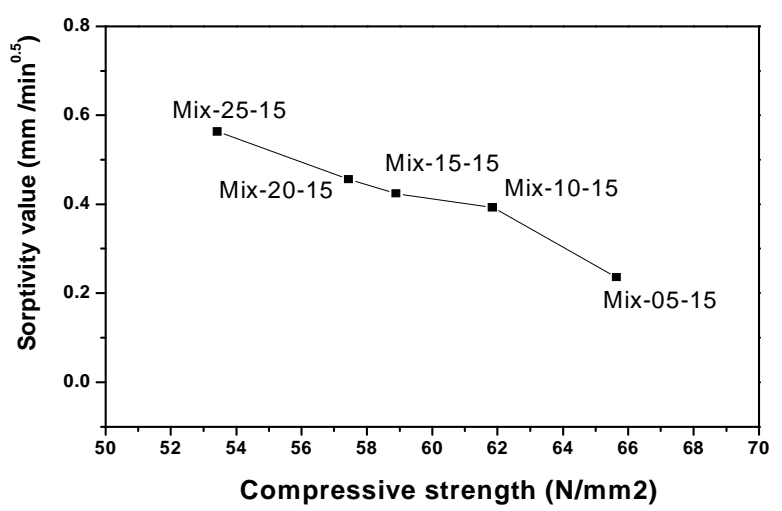

Fig.8 Relationship between sorptivity and compressive strength for mixtures content different ratios $5 \%, 10 \%, 15 \%, 20 \%$ and $25 \%$ of CKD and $15 \% \mathrm{SF}$

\subsection{ACCELERATED CORROSION}

Accelerated corrosion test were conducted on samples of control mixture $(0 \%$ Cement kiln dust and $0 \%$ Silica fume) and mixtures; (5\% Cement kiln dust and 15\% Silica fume), (10\% Cement kiln dust and 15\% Silica fume), (15\% Cement kiln dust and 15\% Silica fume), (20\% Cement kiln dust and 15\% Silica fume). (25\% Cement kiln dust and 15\% Silica fume) at age 28 days to investigate the effect of cement kiln dust with silica fume on corrosion resistance of concrete. Accelerated corrosion test were performed for all specimens based on ASTM G1-03[15]. The cube specimens (150 mm X150 mm X $150 \mathrm{~mm}$ ) were built with steel bar $10 \mathrm{~mm}$ diameter. Steel bar and concrete are only bonded in half length of the cubic specimen, in order to exclude an eventual confinement of the concrete surrounding the rebar due to the stress distribution on the specimen surface in contact with testing rig. During the specimen casting, concrete was placed in the moulds in the perpendicular direction of the bars as shown in Fig.9. The corrosion analysis was performed by A Potentiostat/Galvanostat (EG\&G model 273). A three-electrode cell composed of a specimen as a working electrode, graphite counter electrode, and $\mathrm{Ag} / \mathrm{AgCl}$ reference electrode were used for the tests as shown in Fig.10. Polarization tests were carried out at a scan rate of $0.2 \mathrm{mV} / \mathrm{s}$ at room temperature. Specimens with exposed surface area of $20 \mathrm{~cm} 2$ were used as a working electrode. The Open circuit potential tests for all mixes were performed for 60 days. Specimens were immersed in $3.5 \%$ wt. $\mathrm{NaCl}$ solution for a period of 3 days before electrochemical tests. The PAR CalcTafel Analysis routine statistically fits the experimental data to the Stern-Geary model for a corroding system. The routine automatically selects the data that lies within the Tafel region $( \pm 250 \mathrm{mV}$ with respect to the corrosion potential). It then calculates the corrosion current and the corrosion rate. The solutions were prepared using analytical reagent grade chemicals and distilled water.

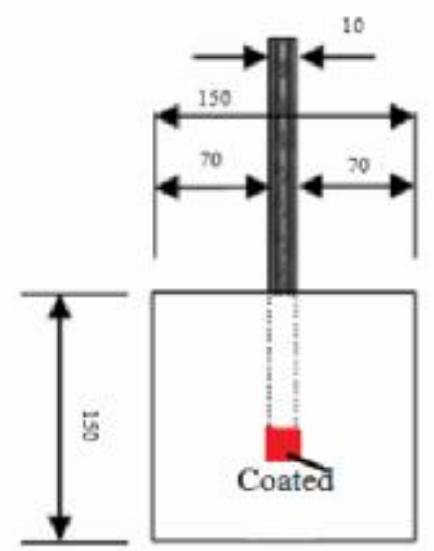

Fig.9 Cross-section of the corrosion specimens 


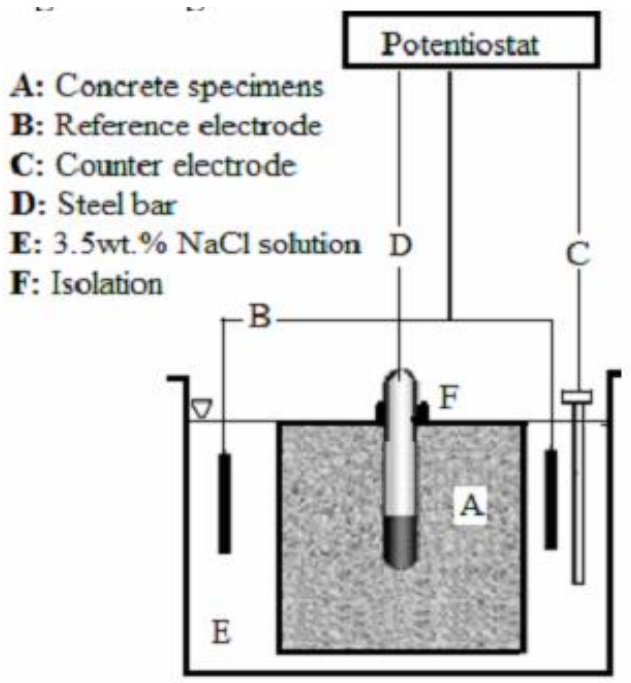

Fig.10 Experimental setup of electrochemical corrosion measurements

\subsubsection{Open circuit potential (OCP)}

Fig.11 shows the potential-time curves of steel bars imbedded in concrete for mixtures with different ratios of cement kiln dust 5\%,10\%,15\%,20\% and $25 \%$ in the presence $15 \%$ silica fume versus control mixture at 28 days in 3.5 wt. $\% \mathrm{NaCl}$ solution. The results show that replacing cement with cement dust kiln and silica fume, the OCP shifts in the negative direction. However, when passing more time the value of OCP is close to each other. This behavior is attributed to the same composition and structure as shown in SEM morphology.

\subsubsection{The corrosion rate}

Fig.12 shows the corrosion rate of steel bars imbedded in concrete for mixtures with different ratios of cement kiln dust 5\%,10\%, 15\%, 20\% and 25\% in the presence $15 \%$ silica fume versus control mixture at 28 days in $3.5 \mathrm{wt}$. $\% \mathrm{NaCl}$ solution. The results indicate that replacing cement with cement dust kiln and silica fume, give close corrosion rate .The results are in agreement with potential-time values. This behavior is owing to the same composition and structure of concrete as shown in SEM morphology.

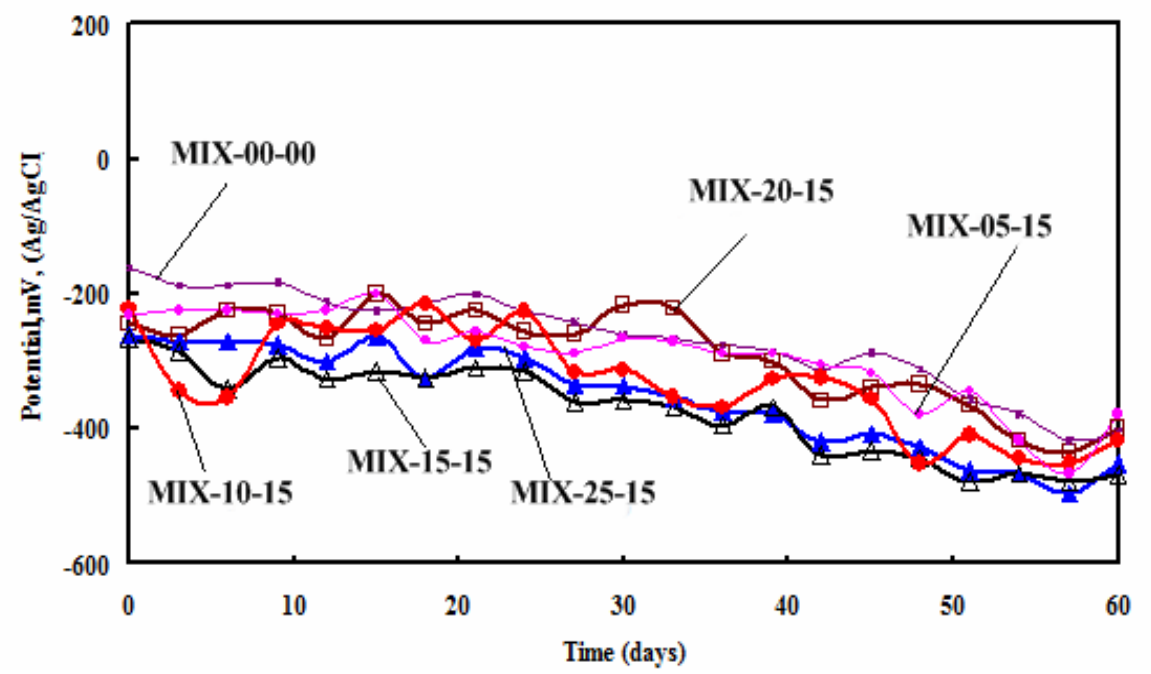

Fig.11 Potential-time curves of steel bars imbedded in concrete for mixtures $(5 \%, 10 \%, 15 \%, 20 \%$ and $25 \%$ ) CKD and constant $15 \%$ SF and control mixture in 3.5 wt. \% NaCl solution 


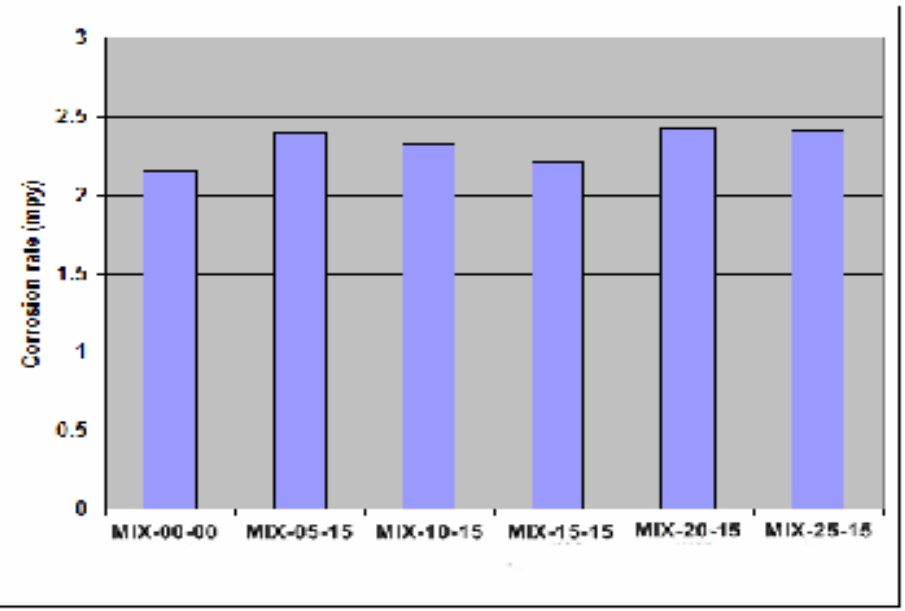

Fig.12 Corrosion rate of reinforced steel bars imbedded in concrete for mixtures $(5 \%, 10 \%, 15 \%, 20 \%$ and $25 \%$ ) CKD and constant $15 \% \mathrm{SF}$ and control mixture in $3.5 \mathrm{wt}$. \% NaCl solution

\subsection{3- Relationship between corrosion rate and compressive strength}

Fig.13 shows the relationship between the 28-day corrosion rate and compressive strengths of concrete mixtures with different ratios of cement dust kiln 5\%,10\%, 15\%, 20\% and 25\% in the presence $15 \%$ silica fume. It is observed at 5\%,10\% and $15 \%$ cement dust kiln amount, corrosion rate are decreased by the decreasing in compressive strength, whereas at $20 \%$ and $25 \%$ cement dust kiln amount the role of compressive strength on corrosion rate can be neglected. By analysis of the present test results, ratio of corrosion rate are equal $3.65 \%$ to $4.51 \%$ from compressive strength table.3.

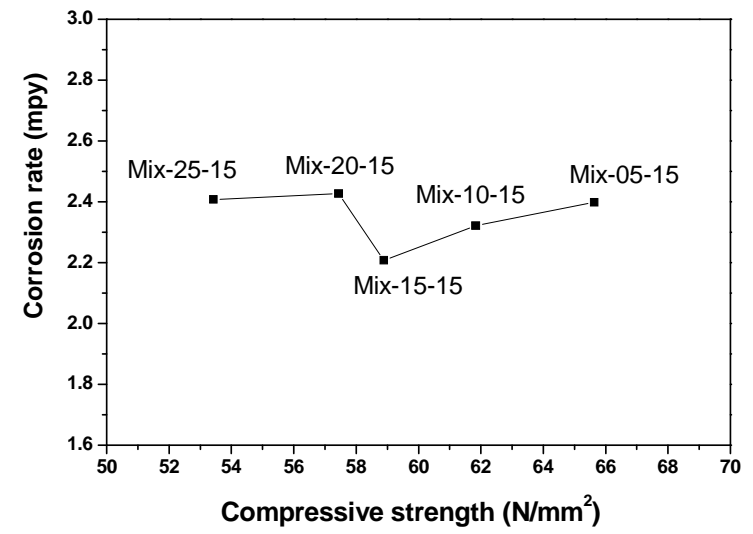

Fig.13 Relationship between corrosion rate and compressive strength

Table.3 Ratio of Corrosion rate from Compressive strength

\begin{tabular}{cl}
\hline Mix & Ratio\% \\
\hline Mix-00-00 & 3.88 \\
Mix-05-15 & 3.65 \\
Mix-10-15 & 3.75 \\
Mix-15-15 & 3.75 \\
Mix-20-15 & 4.23 \\
Mix-25-15 & 4.51 \\
\hline
\end{tabular}




\section{5- X-RAY DIFFRACTION (XRD) ANALYSIS}

When compare XRD analysis results for mixtures content different ratios 5\%, 10\%, 15\%, $20 \%$ and $25 \%$ of cement dust kiln in the presence constant ratio $15 \%$ of silica fume with control mixture Fig.14. The same main minerals are observed for all mixtures in the shape of [Quartz or Quartz, syn (SiO2), Dolomite (Ca Mg ( CO3 )2) and Calcite or Calcite, syn (Ca CO3) ]. The quartz or quartz, syn are was increase with increased cement dust kiln ratio up $25 \%$, the dolomite was increase with increased cement dust kiln ratio up $20 \%$ and calcite or calcite, syn was increase with increase cement dust kiln ratio up 15\%. In general no significant influence on main minerals of concrete mixtures with increase cement dust kiln ratio in the presence of $15 \%$ silica fume as a secondary agent.

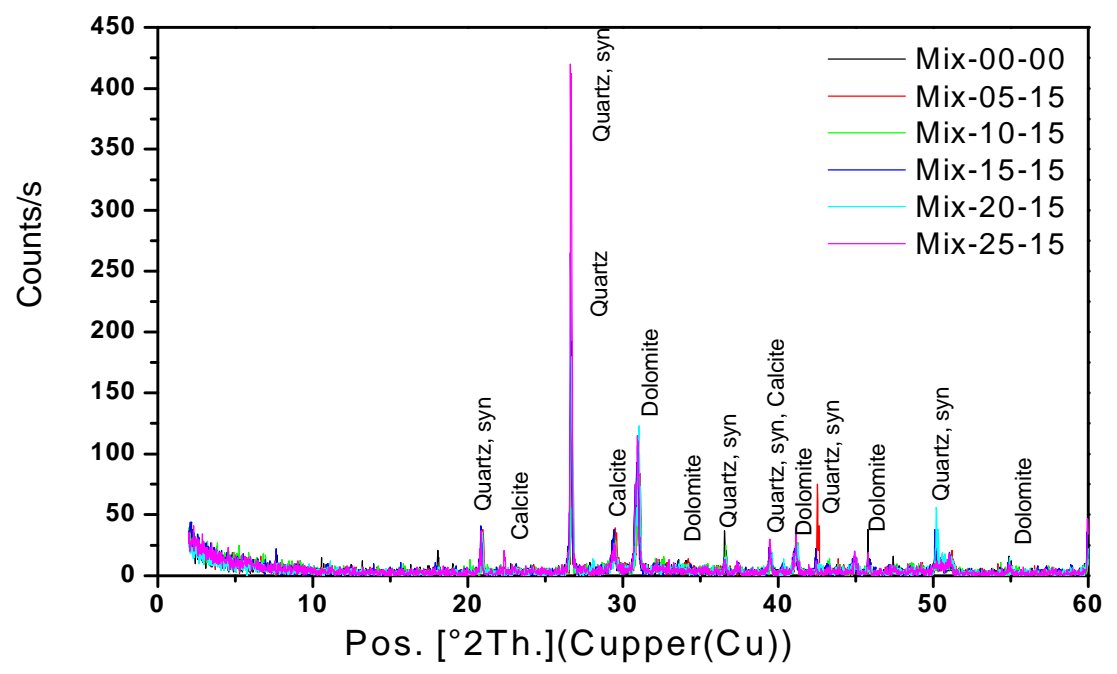

Fig.14 Comparison between XRD analysis for concrete mixtures at 5\%, 10\%, 15\%, 20\% and 25\% CKD in the presence constant ratio $15 \%$ of $\mathrm{SF}$ and control mixture

\section{CONCLUSIONS}

1. We can used industrial wastes as CKD and SF to produce economic concrete. The use of CKD as partial replacement of cement in combination with SF in concrete were shown best performance than use CKD only.

2. The amount of $20 \%$ CKD in the presence $15 \%$ SF as a partial replacement by weight of cement were the optimum ratios can be used in concrete mixtures without lower on compressive. its observed in mixtures at amount of 5\%,10\%, 15\% and $20 \%$ Cement kiln dust in the presence constant amount $15 \%$ Silica fume, the compressive strength are increased with $18.34 \%, 11.48 \%, 6.17 \%$ and $3.55 \%$ respectively. Whereas at mixture at amount $25 \%$ Cement kiln dust and $15 \%$ Silica fume, compressive strength are decreased with $3.69 \%$ when comparison with control mixture.

3. Generally it was observed the value of electrical conductivity $(\sigma)$ directly proportional to the increase of $\mathrm{AC}$ frequency for all mixtures. for mixtures content $5 \%, 10 \%$ and $15 \% \mathrm{CKD}$ in the presence constant $15 \% \mathrm{SF}$ at frequencies $0.12,1.0$ and $10 \mathrm{kHz}$, it was observed the electrical connectivity $(\sigma)$ are increased with increase CKD amount. whereas beyond $15 \%$ CKD amount the electrical connectivity $(\sigma)$ are decreased with increase CKD amount at all frequencies when comparison with control mixture.

4. For all mixtures contained of cement kiln dust and silica fume, the dielectric constant $(\varepsilon)$ less than control mixture at all frequencies. That's mean by using cement kiln dust and silica fume in concrete mixtures lead to decrease the dielectric constant.

5. At all frequencies $0.12,1,10$ and $100 \mathrm{kHz}$, it was found the electrical conductivity $(\sigma)$ increase with decrease compressive strength up to $15 \%$ cement kiln dust, whereas observed beyond $15 \%$ cement kiln dust, the electrical connectivity $(\sigma)$ sharp decreases with decrease compressive strength up to $25 \%$ cement kiln dust. 
6. At amount of 5\% CKD and $15 \% \mathrm{SF}$ as partial replacement of cement, the sorptivity value was decreased with $18.34 \%$. Whereas the sorptivity value were increased with $35.99 \%, 46.71 \%, 57.79 \%$ and $94.81 \%$ at amount of $10 \%, 15 \%, 20 \%$ and $25 \%$ CKD in the presence $15 \%$ SF respectively when compared with control mixture.

7. For all mixtures containing on CKD and SF as partial replacement of cement, the water sorptivity increase with decreasing of compressive strength.

8. The replacing of cement with CKD and SF, give close corrosion rate .The results are in agreement with potential-time values. This behavior is owing to the same composition and structure of concrete as shown in SEM morphology.

9. It is observed at 5\%,10\% and $15 \% \mathrm{CKD}$ amount in the presence $15 \% \mathrm{SF}$, corrosion rate are decreased by the decreasing in compressive strength, whereas at $20 \%$ and $25 \%$ $\mathrm{CKD}$ amount the role of compressive strength on corrosion rate can be neglected. The ratio of corrosion rate are equal $3.65 \%$ to $4.51 \%$ from compressive strength.

10. The presence of cement kiln dust and silica fume as replacing of cement not effect on the main minerals of concrete, it's clear shown from XRD analysis.

\section{REFERENCES}

1. Naiim, K. B., Al-Jumaily, I., \& Atea, A. M. (2016). Characterization of sustainable high performance/self-compacting concrete produced using CKD as a cement replacement material. Construction and Building Materials, 103, 123-129.

2. Siddique, R., \& Raior, A. (2012). Use of cement kiln dust in cement concrete and its leachate characteristics. Resources, Conservation and Recycling, 61, 59-68.

3. Marikunte, S. S., \& Nacer, S. (2012). Interaction of Silica Fume and Water Content on Strength and Permeability of Concrete (No. 12-1733).

4. Marku, J., Dumi, I., Lico, E., Dilo, T., \& Cakaj, O. (2012). The characterization and the utilization of cement kiln dust (CKD) as partial replacement of Portland cement in mortar and concrete production. Zaštita materijala, 53(4), 334-344.

5. Kumar, R., \& Dhaka, J. (2016). Review paper on partial replacement of cement with silica fume and its effects on concrete properties. International Journal for Technological Research in Engineering, 4(1).

6. Roy, D. K. S., \& Sil, A. (2012). Effect of partial replacement of cement by silica fume on hardened concrete. International Journal of Emerging Technology and Advanced Engineering, 2(8), 472-475.

7. Commitee, A. C. I. (1995). Guide for the use of silica fume in concrete. ACI Materials Journal, 92(4), 437-440.

8. Amarkhail, N. (2015). Effects of silica fume on properties of high-strength concrete. Int. J. Tech. Res. Appl, 32, 13-19.

9. The Egyptian standard specifications for concrete aggregates 1109/2002.

10. The Egyptian Standard Specifications 4756/2013. "Testing the physical and mechanical properties of cement".

11. ECP 203-2007. Egyptian code for design and construction of reinforced concrete structures, Design of Concrete Mixes. (2007), pp. (2-28) to (2-34).

12. Egyptian Code for the design and implementation of concrete structures(2007), tests guide C203.

13. Heikal, M., Aiad, I., \& Helmy, I. M. (2002). Portland cement clinker, granulated slag and by-pass cement dust composites. Cement and concrete research, 32(11), 18051812.

14. Al-Harthy, A. S., Taha, R., \& Al-Maamary, F. (2003). Effect of cement kiln dust (CKD) on mortar and concrete mixtures. Construction and Building Materials, 17(5), 353-360.

15. Standard, A. S. T. M. (2011). Standard practice for preparing, cleaning, and evaluating corrosion test specimens. American Society for Testing and Materials G1-03. 